\title{
The effect of social deprivation and gender on self-efficacy beliefs about the postsecondary transition
}

\section{Walter Douglas $^{1}$, Keith Topping $^{2}$}

${ }^{1}$ The Kelvin Centre, Scotland, United Kingdom.

${ }^{2}$ Professor in School of Education, Social Work and Community Education, University of Dundee, Scotland, United Kingdom.

\section{United Kingdom}

Correspondence: Dr Walter Douglas, C Psychol, AFBPsS, Chartered Educational Psychologist, The Kelvin Centre, 3/1, 226 Wilton Street, Glasgow G20 6BJ, United Kingdom. tel: 447870787980, email: walter.douglas@kelvincentre.com

(C) Universidad de Almería and Ilustre Colegio Oficial de la Psicología de Andalucía Oriental (Spain) 


\begin{abstract}
Introduction. High school students' self-efficacy beliefs about their ability to successfully obtain a first postsecondary destination in employment, education or training, and the learning sources of these beliefs were examined.
\end{abstract}

Method. Factor analysis of an inventory administered to 1044 high school students (573 males and 471 females) who attended six urban schools identified five factors.

Results. ANOVA indicated that students living in areas of higher deprivation reported significantly lower levels of positive postsecondary destination self-efficacy belief, and less experience of vicarious career success. Males reported less personal experience of career success than females but higher levels of positive postsecondary destination self-efficacy belief (particularly at higher levels of deprivation). Males reported greater experience of positive career-related emotional arousal.

Discussion and Conclusion. These results may contribute to an explanation of why failure to obtain a positive postsecondary destination is more prevalent in young people living in areas of greater social deprivation, and in males rather than females. The implications for practice, policy and future research are discussed.

Keywords: self-efficacy, learning experiences, social cognitive career theory, postsecondary transition. 


\section{Resumen}

Introducción. Se examinaron las creencias de autoeficacia de los estudiantes de secundaria sobre su capacidad para alcanzar un destino postsecundario positivo en el empleo, la educación o la capacitación, y las fuentes de aprendizaje de estas creencias.

Método. Se realizó un análisis factorial de un inventario administrado a 1044 estudiantes de secundaria (573 niños y 471 niñas) que asistieron a seis escuelas urbanas identificándose cinco factores.

Resultados. El ANOVA indicó que los estudiantes que viven en áreas de mayor privación informaron niveles significativamente más bajos de creencia positiva de autoeficacia en el destino postsecundario y menos experiencia de éxito profesional indirecto. Los hombres informaron menos experiencia personal de éxito profesional que las mujeres, pero niveles más altos de creencia positiva de autoeficacia en el destino postsecundario (particularmente en niveles más altos de privación). Los hombres informaron una mayor experiencia de excitación emocional positiva relacionada con la carrera.

Discusión y Conclusion: Estos resultados pueden contribuir a una explicación de por qué la imposibilidad de obtener un destino positivo después de la secundaria es más frecuente en los jóvenes que viven en zonas de mayor deprivación social y en los hombres que en las mujeres. Se discuten las implicaciones para la práctica, la política y la investigación futura.

Palabras clave: autoeficacia, experiencias de aprendizaje, teoría de la carrera cognitiva social, transición postsecundaria. 


\section{Introduction}

Across the world there has been significant recent research and policy interest in improving the transition from high school to first postsecondary destinations in employment, education or training (e.g. Sanderson, 2019; Hanson, Codina, \& Neary, 2017; Anders \& Dorsett, 2017). Indeed England and Scotland have implemented government policies which guarantee that every school leaver receives a fully-funded offer of a positive first destination, complete with financial incentives to encourage engagement, immediately on leaving school, (Valiente, Lowden, \& Capsada-Munsech, 2020; Cooke, 2013; Scottish Government, 2012a). Despite this a significant number of young people fail to enter a positive postsecondary destination on leaving school and join the ranks of unemployed youth. It has been shown that being "not in education, employment or training" in the period immediately after leaving school is associated with development of longer term labour market risk (Bäckman \& Nilsson, 2016); social exclusion (Maguire \& Thompson, 2007); higher risk of poor physical and mental health (Feng, Everington, \& Ralston, 2015); and higher risk of drug and alcohol misuse, parenting at a young age, and criminal activity (Simmons, Connelly, \& Thompson, 2020, Coles et al., 2002).

Several studies have shown that high school students from areas of higher social deprivation are over represented in those who fail (e.g. Feng et al., 2015; Schoon, 2020, 2014; Skills Development Scotland, 2014, 2015). Other studies have shown that males are over-represented in those who fail (Feng, et al., 2015; Skills Development Scotland, 2014, 2015; Collins, McLeod, \& Kenway, 2000). These demographic gaps in postsecondary transition attainment represent a significant social justice problem for schools, policy-makers and government decision makers. The present study seeks to explore the possibility that socioeconomic status (SES) and gender differences in the rate at which school leavers fail to obtain a postsecondary destination and become unemployed can be explained in part by detectable differences in their thinking and emotional response to their social environments. Therefore, the study sought to investigate the effect of SES and gender on selfefficacy beliefs that school students held about their ability to obtain a positive postsecondary destination rather than become unemployed on leaving school. The study also examined the effects of SES and gender on students' exposure to the learning experiences that have been postulated as the sources of these self-efficacy beliefs. These included their perceptions of their own past performance, their exposure to role models; the extent to which they have 
received encouraging social persuasion; and their awareness of positive or negative emotional arousal states when they think about the transition challenge they face. This research has the potential to inform educational practice, policy and future research to help close the SES and gender attainment gaps in the achievement of positive postsecondary destinations.

\section{Self-efficacy beliefs about the postsecondary transition}

Self-efficacy belief was originally defined as "people's judgements of their capabilities to organise and execute courses of action required to attain designated types of performance. It is concerned not with the skills one has but with judgements of what one can do with whatever skills one possesses," (Bandura, 1986, p.391). Bandura also noted that, "competent functioning requires both skills and self-beliefs of efficacy to use them", (Bandura, 1986, p.391). Self-efficacy beliefs are central and pervasive mechanisms in personal agency, which have been shown to determine a person's choice of behaviours and environments, as well as the amount of effort and persistence a person expends and the responses they make in the face of aversive experiences and obstacles (Bandura, 1977, 1989). Crucially, Bandura $(1977,1989)$ showed that self-efficacy beliefs were causally related to domain-specific target behaviors.

A Career Self-Management Model (CSM) has been posited by Lent and Brown (2013) and subsequently developed and empirically supported by Brown and Lent (2018) and by Lent, Ireland, Penn, Morris, \& Sappington (2017). This was built on the earlier framework of Social Cognitive Career Theory (SCCT) (Lent, Brown, \& Hackett, 1994), which was derived from (Bandura, 1989, 1977). A key hypothesis within these models was that greater experience of four different career-relevant learning experiences acted as sources of career self-efficacy, which included personal past performance accomplishments, observational learning or modelling, social encouragement, and physiological affective states and reactions. Brown and Lent (2018) and Lent et al. (1994) postulated that, within the career domain, exposure to these sources resulted in greater career self-efficacy beliefs, which influenced outcome expectations, goal-setting and performance of career outcome attainment behaviours in turn.

Lent et al. (2017) provided empirical support for a path model which included the four different career-relevant learning experience variables in the prediction of career exploration goals and level of career decidedness. Other studies have confirmed similar transmission 
pathways between the four learning sources and self-efficacy beliefs about academic performance rather than career performance, although most of these studies have been carried out with a particular emphasis on science, technology and mathematics (Echeverría Castro, Sotelo Castillo, Acosta Quiroz, \& Barrera Hernández, 2020; Ahn, Bong, \& Kim, 2017; Butz \& Usher, 2015; Usher \& Pajares, 2008). However, it is significant that no study was found which tested these hypothesised relationships in respect of the self-efficacy beliefs of high school students about their ability to perform the specific target behaviour of entering a positive postsecondary destination, rather than becoming unemployed.

It has also been postulated within SCCT and SCM that person variables including SES and gender would have effects on these transmission processes (Lent \& Brown, 2013; Lent, Brown, \& Hackett, 1994, 2000). This has been postulated to occur in two different ways. Firstly, SES and gender could exert proximal effects by influencing learning experiences, which in turn could influence self-efficacy beliefs. Secondly, SES and gender could have a more distal effect by influencing the conversion of self-efficacy beliefs into goals and performance attainment behaviours. A search of the literature revealed a scarcity of studies in this specific area. However, two studies were found that measured the relationships between learning sources and career self-efficacy beliefs, which also sought to investigate the effects of these person factors.

The first of these studies, by Anderson and Betz (2001), examined these processes in the domain of career decision-making ability in university students in the USA. This entailed the customised development of the Sources of Social Self-Efficacy Scale (SSSS) to measure exposure to hypothesised learning sources of social self-efficacy as broadly defined, including past performance, vicarious experience, social persuasion and emotional arousal. Social self-efficacy was measured using the pre-existing Social Confidence Scale (SCS) from the Skills Confidence Inventory (Betz, Borgen, \& Harmon, 1996). Bandura (2006) and Betz and Hackett (2006) have stressed that self-efficacy beliefs and associated constructs have greatest salience when measured in closely focused, domain-congruent ways. Therefore, it could be argued that these generic measures lacked this requirement for closely focused, parallel specificity. Nevertheless, Anderson and Betz (2001) showed that males reported significantly lower scores than females for past performance, vicarious experience and social persuasion. There was no gender difference on emotional arousal. Analysis of variance as a function of students' reports of whether they had selected a career or not showed that students 
who had decided on a career also reported greater exposure to past performance, vicarious experience, social persuasion, and emotional arousal; and had greater social self-efficacy beliefs.

The second study, Chin and Kameoka (2002) was uniquely salient in that it involved high school students in the USA and investigated the inter-relationships between self-efficacy beliefs about future career attainment, the hypothesised learning sources of these beliefs, and SES. A measure entitled the Self-Efficacy Scale for Future Attainment (SSFA) was custommade to assess self-efficacy beliefs for postsecondary educational and occupational attainment. This contained nine items which purported to measure postsecondary educational self-efficacy. An example item from this was "I will probably go to college". It also contained another nine items which purported to measure postsecondary occupational selfefficacy. An example item for this was "I will have the job I want". Such items appeared to have good content validity for the target constructs of achieving postsecondary educational and occupational success, respectively. However, strictly speaking, such items deviated significantly from the main tenets of social cognitive theory. Within social cognitive theory, self-efficacy is concerned with perceived capability and so scale items should be phrased as can do rather than will do (Bandura, 2006, p.308).

Nevertheless, using multiple regression analyses Chin and Kameoka (2002) showed that social persuasion was a significant predictor of occupational self-efficacy beliefs but that vicarious experience was not. Chin and Kameoka (2002) found that SES did not predict the measured level of exposure to any of the putative learning sources of self-efficacy beliefs, nor did SES predict the postsecondary educational or occupational self-efficacy beliefs of the participants. It is important to note, however, that SES was measured within the study by asking participants about their perceptions about neighbourhood resources and safety, which is a problematic measure of SES.

Taken together these latter two studies give a tantalising glimpse of the potential of this under researched area to contribute to a better understanding of the SES and gender gaps in the attainment of positive postsecondary destinations in school leavers. However, they also highlight some substantial measurement limitations in terms of domain specificity and theoretical coherence of social cognitive measures, and in failure to capture the multidimensional nature of SES. The current study therefore sought to develop new measures 
of self-efficacy belief and associated learning sources that related specifically to the target behaviour of obtaining a positive postsecondary destination in employment, education or training, as opposed to becoming unemployed immediately on leaving school. The study also sought to investigate the effects and interactions of SES and gender on these variables by the application of a more robust multidimensional measure of SES.

\section{Objectives and Hypotheses}

The objective of the the current study was to generate new insights that could inform educational practice, policy and future research, in order to close the identified SES and gender discrepancies in the attainment of immediate postsecondary destinations. Therefore the study sought to explore following hypotheses.

1. Participants from lower socioeconomic backgrounds, and males, will report lower levels of self-efficacy beliefs that they can obtain a positive postsecondary destination in education, employment or training.

2. Participants from lower socioeconomic backgrounds, and males, will report lower exposure to the learning experiences that are putative sources of these self-efficacy beliefs including: past performance; vicarious experience; social persuasion; and emotional arousal.

\section{Method}

\section{Participants}

The participants were 1044 senior high school students (573 males and 471 females) who attended six urban high schools from a single school district in Scotland, UK. In Scotland young people attend the same secondary school throughout their education as no sixth form colleges operate in Scotland, as in other countries in the United Kingdom. The participants were in the senior phase of this system in secondary years 4, 5 and 6, which offers subjects including science, mathematics and technology; languages; expressive arts and humanities; and social sciences. In secondary 4 students undertake 6-9 subjects called National 3 but there is no external exam. At levels National 4 and National 5 external examinations start. After these qualifications, students study for Highers, usually in five subjects. These take a year to complete, after which some students apply to college or university or stay on for a further year when other Highers are gained, or Advanced Highers are studied. 
The research area included a total of nine secondary schools. A school which was in the middle of the range of SES present in the school district as a whole was chosen to pilot the questionnaire. The participants for the questionnaire pilot study comprised two focus groups of eight participants, chosen using a stratified sampling technique to replicate the whole participant population, in terms of age, SES and gender. The six participant schools for the main study were selected from eight remaining schools in the accessible research area, based on the following criteria. Two schools were excluded from the research sample because they were atypical: one because it was a female-only school and the other because it delivered the curriculum in Gaelic. This provided a sample population which covered the complete range of SES present in the study area but skewed towards higher levels of deprivation in comparison to the overall Scottish population. The age of the participants ranged from 15 years 0 months to 19 years 1 month, with a mean of 16 years 6 months ( $\mathrm{SD}=8.1$ months). The sample represented $57 \%$ of the total population of secondary years 4 , 5 and 6 in the six participant schools.

\section{Instruments}

A questionnaire designed to measure five social cognitive factors was used. These included Positive Destination Self-Efficacy beliefs and the four hypothesised learning sources for these beliefs including, Past Performance, Vicarious Experience, Social Persuasion, and Emotional Arousal. A total of eleven questionnaire items included three relating to Positive Destination Self-Efficacy, and eight relating to the four learning source constructs.

As recommended by Bandura (2006), participants were requested to rate each of the self-efficacy items on a scale of 0-100 according to their degree of confidence that they could successfully carry out the specified action. A response of 0 indicated no confidence at all, through to a score of 100 which indicated complete confidence. Participants were required to place a cross on a continuous line, graduated in units of 10 , choosing their response from any possible position along the continuum. A different response format was used for the learning source ítems. Participants were asked to rate the degree to which they agreed with the item statement in question. A response of 0 indicated Strongly Disagree through to a score of 100 which indicated Strongly Agree. As before, the participants were required to place a cross on a continuous graduated line from 0 to 100 . 
The SES variable was obtained using the Scottish Index of Multiple Deprivation (SIMD) which enabled the identification of the social deprivation ranking (1-6505) of the residential location of each participant based on their address. This was achieved using the on-line post-code look-up facility for the SIMD which is operated and maintained by the Scottish Govenment to support policy reasearch and development. The SIMD is a weighted index of 38 indicators across seven domains including: income; employment; health; education, skills and training; housing; geographic access; and crime, (Scottish Government, 2013, 2012b). This provided an authoritative and highly sensitive, multi-dimensional measure of SES based on small and finely graded geographical data zones. This allowed the identification of the quintile segment of deprivation for the geographical location in which each participant lived, relative to the whole national population. Three levels of the independent variable SES were established including participants from (1) quintile 1 on the index of deprivation $(N=474)$, (2) quintiles 2 and $3(N=329)$, and (3) quintiles 4 and 5 $(N=233)$. The independent variable of gender was applied at two levels: male and female.

\section{Procedure}

Questionnaire items were generated from three sources including: (a) a literature review on SCCT, CSM, and other associated social cognitive constructs, particularly in direct relation to young people preparing for the postsecondary transition (e.g. Lent et al., 2017; Butz \& Usher, 2015; Lent \& Brown, 2013; Bandura, 2006; Bong, 2006; Lent at al., 2000; Lent et al., 1994); (b) existing questionnaires and inventories (e.g. The Career Decision Selfefficacy Scale (CDSES) (Betz \& Taylor, 2013; Betz, Klein, \& Taylor, 1996); The Skills Confidence Inventory (SCI), (Betz, Borgen, \& Harmon,1996); and The Sources of Social Self-efficacy Scale (SSSS), (Anderson \& Betz, 2001) and; (c) items originated by one of the authors who was a practicing Educational Psychologist.

Before the commencement of the study, ethics approval was sought and obtained from two sources. These included the University of Dundee Research Ethics Committee and the Research Consultancy Group at the Psychological Service in the Local Education Authority (LEA) which hosted the research. Informed, written consent for the research, based on the principles of full disclosure and penalty-free withdrawal, was also obtained at four different systemic levels including (a) the Directorate of the host LEA, (b) the Head Teachers of the six participating schools, the (c) participants, and (d) their parents. 
The pilot questionnare was administered to two focus groups by one of the authors. A focus group question sheet was then used to elicit partcipant views on how effective the questionnaire was in finding out what young people think, feel and do as they prepare to leave school. The verbal resposes of focus group members were audio recorded. The wording of the items was modified in response to participant feedback. The final questionnaire was administered directly by one of the authors. Each school received two visits to enable adequate sampling of the population.

\section{Data Analysis}

The study used a $3 \times 2$ between-subjects design. The independent variables were SES at three levels and gender at two levels. The dependent variables were participant scores on questionnaire scales measuring self-efficacy and the four learning sources of self-efficacy. The statistical software package used for this purpose was the Statistical Package for the Social Sciences (SPSS) v. 21. Factor analysis of the scores on the questionnaire items was used to identify statistical clustering of component items. The items relating to self-efficacy beliefs were factor analysed separately from the items relating to the sources of self-efficacy, as they were theoretically distinct and employed a different scale of measurement. Factor extraction was carried out on the scores on the Positive Destination Self-Efficacy items using Principal Components Analysis (PCA) based on Eigenvalues greater than one and rotated using orthogonal equamax rotation. Factor extraction was carried out on the scores on the learning sources items using PCA based on a fixed number of four factors with orthogonal equamax rotation. Two-way ANOVA was then used to explore the relationship between participants' scores on each of the five scales, and SES and gender.

\section{Results}

\section{Factor analysis}

\section{Positive Destination Self-Efficacy}

The data were checked to determine if they were appropriate for Exploratory Factor Analysis (EFA) in accordance with the procedure recommended by Brace, Kemp and Snelgar (2012). No item deviated substantially from the mean. A Bartlett test of sphericity showed $\chi^{2}(15 \mathrm{df})=3469.82, p<.001$, indicating there were discoverable relationships within the data. A Kaiser-Meyer-Olkin (KMO) test was carried out to determine whether the inter- 
correlations between the items could be accounted for by a smaller set of factors. The average KMO for the initial matrix was 0.889 , which was substantially greater than the .5 minimum recommended by Brace et al. (2012), indicating suitability for factor analysis. The scree test was examined as recommended by Cattell (1966), which suggested a single factor solution accounting for $81.01 \%$ of the variance. The single factor structure is shown in Table 1 . The alpha coefficient was .88 which exceeded .7 and was therefore adequate (Brace et al. 2012).

Table 1. Factor structure of the Positive Destination Self-Efficacy Scale

\begin{tabular}{lr}
\hline Questionnaire items & $\mathbf{. 8 9}$ \\
\hline SE1. I can start a good career when I leave & \\
school. & $\mathbf{. 9 0}$ \\
SE2. I can get into employment, education & \\
or training after school. & $\mathbf{9 0}$ \\
SE3. I can avoid being unemployed when I & \\
leave school. & 2.43 \\
Eigenvalue & 81.01 \\
\% of variance & .88 \\
Cronbach's alpha & 73.53 \\
Mean & 20.03 \\
SD
\end{tabular}

Note: Eigenvalue > 1. Loadings for each item are shown in bold print

\section{Career Learning Experiences}

Again no item deviated substantially from the mean. A Bartlett test of sphericity on the initial correlation matrix showed $\chi^{2}(28 \mathrm{df})=1268.46, p<.001$ indicating that there were discoverable relationships within the data. The KMO for the initial matrix was 0.754, substantially greater than the .5 minimum. Within a fixed four factor model a single item was found to have a loading below .3, which was "I have already experienced some success in my education." This item was removed from the analysis, and the remaining seven items factor analysed again. This produced a simple, interpretable structure with consistently high loadings shown in Table 2. The alpha coefficients for Social Persuasion, Vicarious Experience and Emotional Arousal were .67, .63, .64 respectively, which were all approaching .7 and therefore adequate (Brace et al. 2012). 
Table 2. Factor structure of the Sources of Self-efficacy for the Postsecondary Transition Scales

\begin{tabular}{|c|c|c|c|c|}
\hline \multirow[t]{2}{*}{ Questionnaire items } & \multicolumn{4}{|c|}{ Scales } \\
\hline & $\begin{array}{c}\text { Social } \\
\text { Persuasion }\end{array}$ & $\begin{array}{c}\text { Vicarious } \\
\text { Experience }\end{array}$ & $\begin{array}{l}\text { Emotional } \\
\text { Arousal }\end{array}$ & $\begin{array}{c}\text { Past } \\
\text { Performance } \\
\end{array}$ \\
\hline $\begin{array}{l}\text { PP1. I have already } \\
\text { experienced some success } \\
\text { in a part-time job or work } \\
\text { experience. }\end{array}$ & .04 & .06 & .05 & .99 \\
\hline $\begin{array}{l}\text { VE1. I know someone who } \\
\text { has been successful in } \\
\text { going to college or } \\
\text { university after school. }\end{array}$ & .10 & .85 & .06 & .07 \\
\hline $\begin{array}{l}\text { VE2. I know someone who } \\
\text { has been successful in a job. }\end{array}$ & .19 & .81 & .06 & .04 \\
\hline $\begin{array}{l}\text { SP1. I know someone I trust } \\
\text { who tries to persuade me } \\
\text { that I can be successful in } \\
\text { my career after school. }\end{array}$ & .79 & .23 & .08 & .07 \\
\hline $\begin{array}{l}\text { SP2. I know someone who } \\
\text { really believes in my ability } \\
\text { to have a successful career. }\end{array}$ & .85 & .10 & .10 & .03 \\
\hline $\begin{array}{l}\text { EA1. I am confident that I } \\
\text { will be able to continue my } \\
\text { education or get a job after } \\
\text { school and this makes me } \\
\text { feel good }\end{array}$ & .44 & .14 & .62 & .04 \\
\hline $\begin{array}{l}\text { EA2. I am worried that I } \\
\text { will not be able to find } \\
\text { something to do after } \\
\text { school and that makes me } \\
\text { feel bad. }\end{array}$ & .05 & .01 & -.92 & -.05 \\
\hline Eigenvalue & 2.36 & 1.12 & .99 & .87 \\
\hline$\%$ of variance & 33.77 & 16.04 & 14.14 & 12.48 \\
\hline Chronbach's alpha & .67 & .63 & .64 & $\mathrm{~N} / \mathrm{a}$ \\
\hline Mean & 79.07 & 82.94 & 66.21 & 55.90 \\
\hline SD & 21.00 & 20.76 & 20.48 & 38.69 \\
\hline
\end{tabular}

Note: The highest loading for each item is shown in bold print

The relationship between factors and SES and gender

\section{Positive Destination Self-Efficacy Scale}

When a 2-way ANOVA was applied using summed scores on the Positive Destination Self-Efficacy Scale the main effect for deprivation was statistically significant: F $(2,1036)=$ 9.262, $p<.001$, which indicated that participants living in areas of higher deprivation reported fewer self-efficacy beliefs about being able to obtain a positive postsecondary destination 
than those living in more socially advantaged areas. Employing the Bonferroni post-hoc test, a significant difference was found between the High Deprivation and Low Deprivation conditions $(p<.001)$ and between the High Deprivation and Medium Deprivation conditions $(p=.040)$. No significant difference was found between the Medium Deprivation and Low Deprivation conditions ( $p=.242$ ). The main effect of gender was also statistically significant, $\mathrm{F}(1,1036)=11.563, p=.001$, which indicated that males reported greater self-efficacy beliefs than females. There was a statistically significant interaction between these two factors, F (2, $1036)=2.898, p=.05$, which showed that the greater self-efficacy beliefs of males were more marked at higher deprivation. These results are displayed in graphical form in Figure 1.

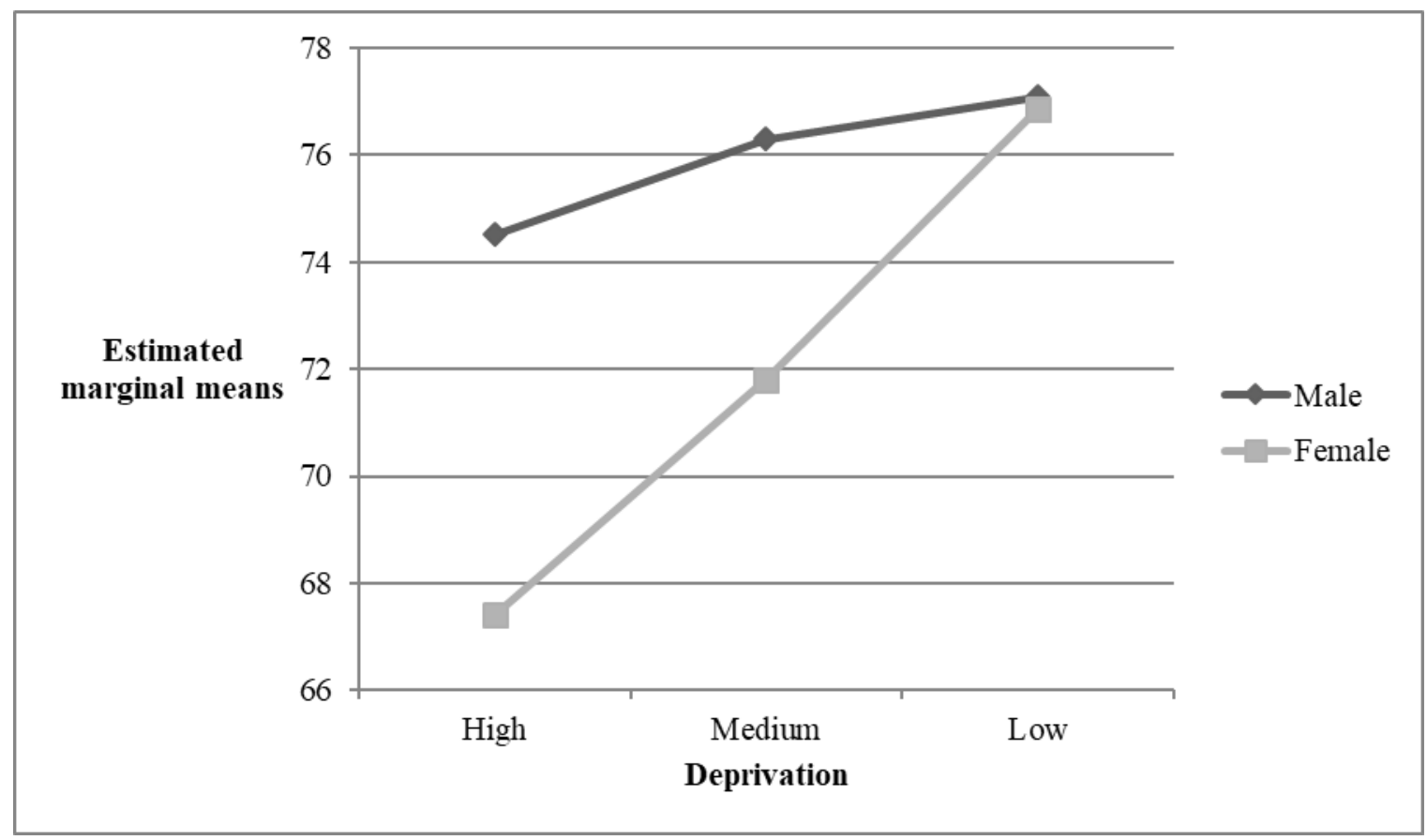

Figure 1. Marginal mean scores on the Positive Destination Self-Efficacy Scale. A higher marginal mean indicates greater positive destination self-efficacy.

\section{Career Learning Experiences: Past Performance Scale}

When a 2-way ANOVA was applied using the summed scores on the Career Learning Experience: Past Performance Scale the main effect of deprivation was not statistically significant, $F(2,1036)=1.502, p=.223$. The main effect of gender was statistically significant, $\mathrm{F}(1,1036)=9.358, p=.002$, indicating that males reported fewer positive perceptions of having experienced previous success in education / employment than females. There was no statistically significant interaction between these two factors, F $(2,1036)=$ $2.008, p=.135$. These results are displayed in graphical form in Figure 2. 


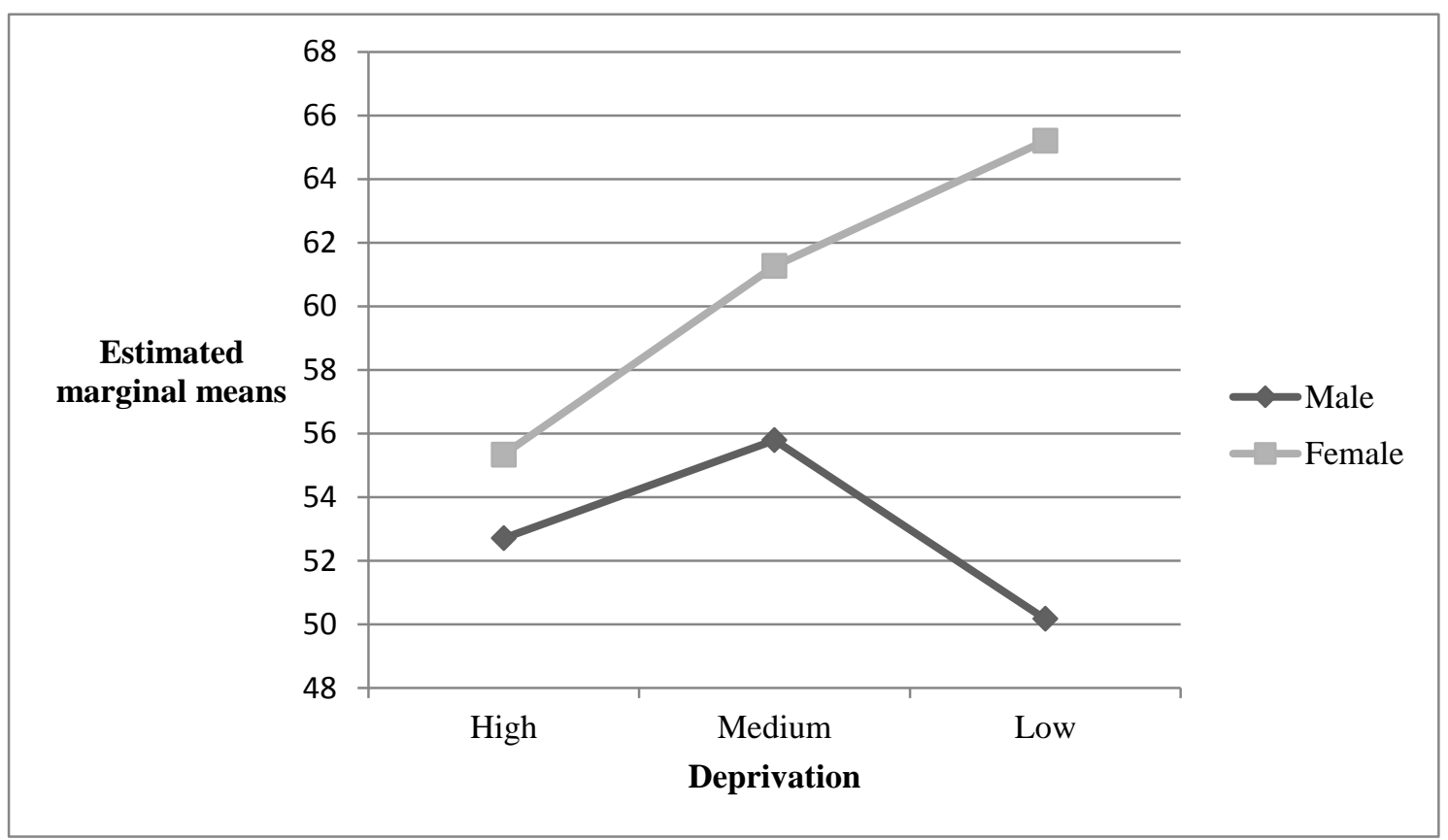

Figure 2. Marginal mean scores on the Career Learning Experience: Past Performance Scale. A higher marginal mean indicates a more positive perception of having experienced previous success in education or employment.

\section{Career Learning Experience: Vicarious Experience Scale}

When a 2-way ANOVA was applied using the summed scores on the Career Learning Experience: Vicarious Experience Scale the main effect of deprivation was statistically significant, $\mathrm{F}(2,1036)=10.049, p<.001$, indicating that participants living in areas of higher deprivation reported less vicarious experience of success in employment or education than participants in more socially advantaged areas. Employing the Bonferroni post-hoc test, a significant difference was found between the High Deprivation and Low Deprivation conditions $(p<.001)$ and between the Medium Deprivation and Low Deprivation conditions $(p=.004)$. There were no significant differences between the High Deprivation and Medium Deprivation conditions ( $p=.840$ ). The main effect of gender was not statistically significant, $\mathrm{F}$ $(2,1036)=2.778, p=.096$. There was no statistically significant interaction between these two factors, $\mathrm{F}(2,1036)=.324, p=.723$. These results are displayed in graphical form in Figure 3. 


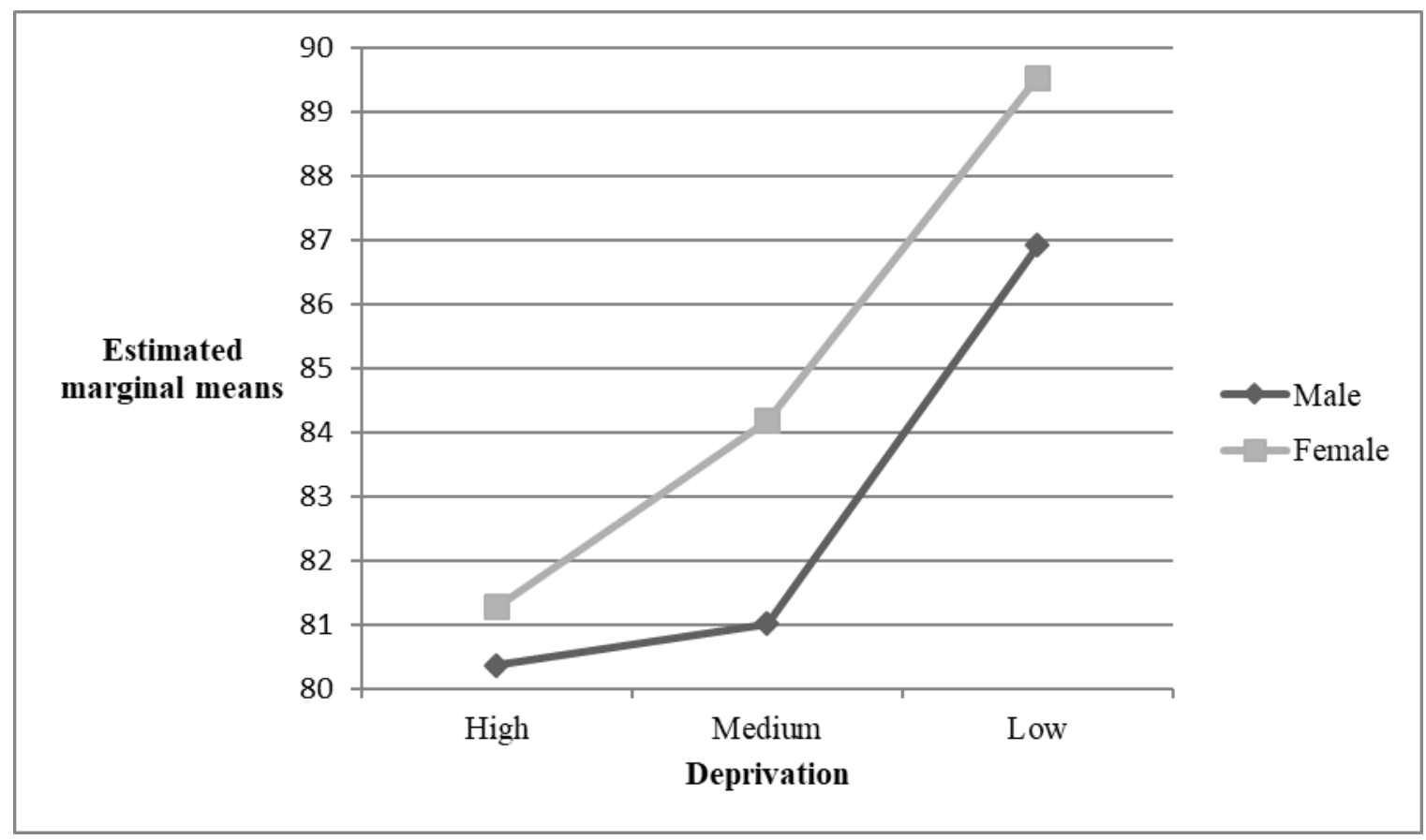

Figure 3. Marginal mean scores on the Career Learning Experiences: Vicarious Experience Scale. A higher marginal mean indicates greater knowledge of others who have been successful in employment or education.

\section{Career Learning Experience: Emotional Arousal Scale.}

When a 2-way ANOVA was applied using the summed scores on the Career Learning Experience: Emotional Arousal Scale the main effect of deprivation was not statistically significant, $\mathrm{F}(1,1036)=2.175, \mathrm{p}=.114$. The main effect of gender was statistically significant, $\mathrm{F}(1,1036)=29.518, \mathrm{p}<.001$, indicating that males reported more positive emotional arousal and less negative emotional arousal in relation to thinking about the postsecondary transition. There was no statistically significant interaction between these factors, $\mathrm{F}(2,1036)=1.753, p=.174$. These results are displayed in graphical form in Figure 4. 


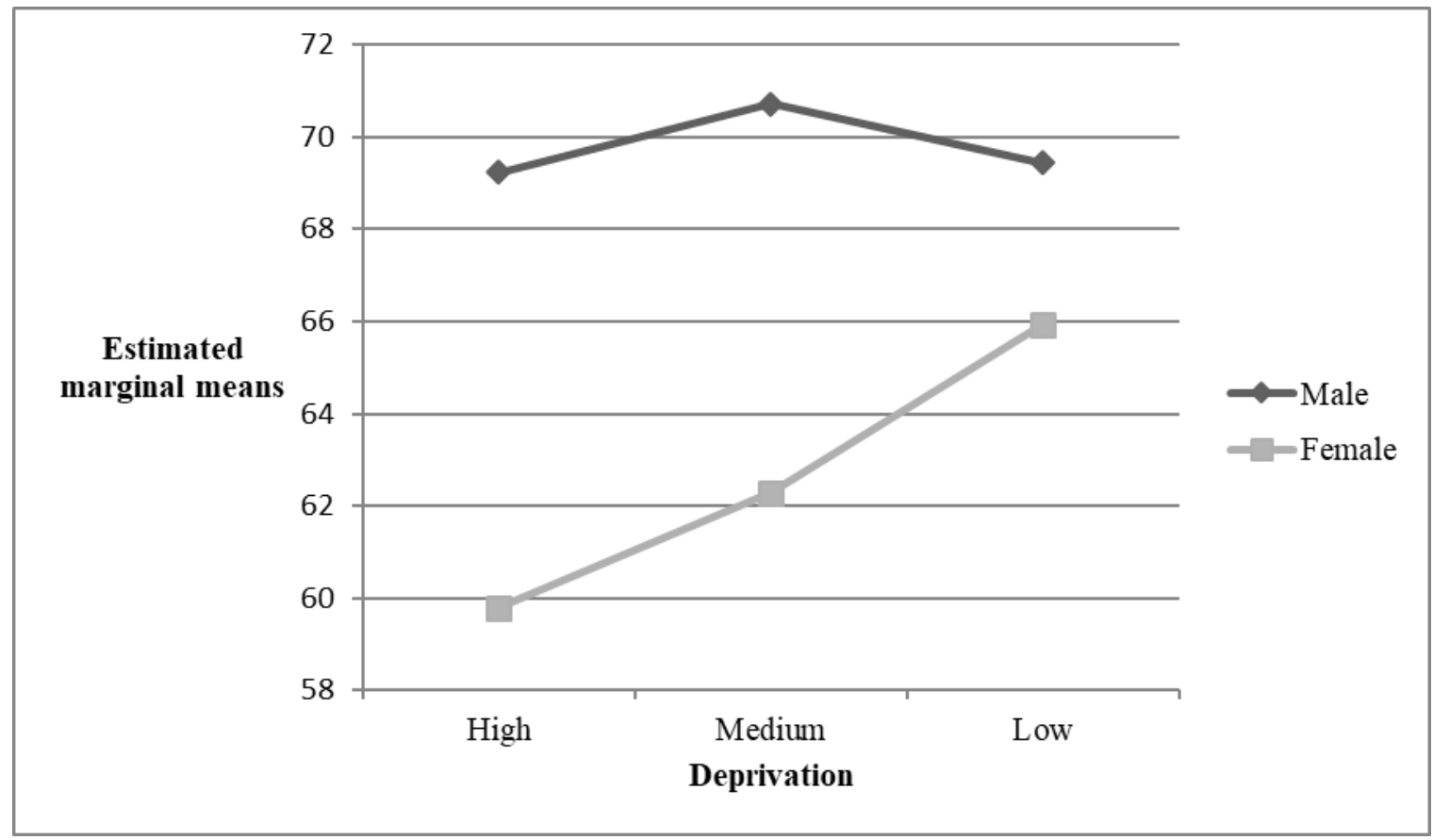

Figure 4. Marginal mean scores on the Career Learning Experience: Emotional Arousal Scale. A higher marginal mean indicates more positive emotional arousal and less negative emotional arousal in relation to the postsecondary transition.

\section{Discussion and Conclusion}

\section{Self-efficacy Beliefs and SES}

The results show that high school students who lived in areas of higher deprivation reported significantly fewer positive postsecondary destination self-efficacy beliefs. This finding could contribute to an explanation of the fact that young people living in areas of greater social deprivation are more likely to fail to attain a positive postsecondary destination when they leave school. This possibility is consistent with previous research carried out within a generic social cognitive framework. For example, Bandura $(1997,1989)$ reported that people who had greater self-efficacy belief that they could execute a particular behaviour were also more likely to show greater personal agency in that specific domain of functioning. Previous research has also indicated that greater self-efficacy beliefs can predict an individual's choice of behaviours and environments, as well as the amount of effort and persistence they will expend (Bandura, 1989, 1997). Crucially, it has also been previously 
shown that self-efficacy beliefs can predict the responses that a person will make in the face of set-backs and difficulties (Bandura, 1989, 1997).

The possibility that the fewer postsecondary destination self-efficacy beliefs reported by high school students living in areas of greater social deprivation may be a contributory factor to their lower rates of success in achieving a positive destination is also highly consistent with the relevant tenets of SCCT (Lent, Brown, \& Hackett, 1994), and CSM (Brown \& Lent, 2018; Lent \& Brown, 2013). Viewed from the perspective of these theoretical frameworks, individuals who have greater self-efficacy belief that they can achieve a positive postsecondary destination would be more likely to form interests in specific postsecondary destinations in employment, education and training; and then go on to set specific and challenging career activity goals. The SCCT and CSM frameworks suggest that setting more challenging career activity goals would in turn result in individuals exposing themselves to experiences which would create the possibility of positive reinforcement, and thus establish an iterative, constructive feedback loop with positive postsecondary destination self-efficacy beliefs.

\section{The Sources of Self-Efficacy Beliefs and SES}

The results showed that high school students who lived in areas of higher deprivation reported significantly lower scores for vicarious experience. This indicated that they were less likely to report that they knew someone who they perceived as having been successful in a job or in education after leaving school. This result is congruent with the core predictions of social cognitive theory as outlined by Bandura (1986) and with the core predictions of the CSM posited by Brown and Lent (2018), Lent et al. (2017), and Lent and Brown (2013). These were that domain-relevant vicarious experience will be associated with increased domain-specific self-efficacy belief, and together these factors would be associated with greater performance of the target behaviour. In consequence, it is possible to argue that high school students living in areas of greater deprivation had less exposure to positive role models demonstrating postsecondary success behaviours, and as a result had less positive postsecondary self-efficacy beliefs.

This finding is in opposition to that of Chin and Kameoka (2002) who reported no significant difference in career-relevant vicarious experience with regard to SES in high school students in the USA. However, Chin and Kameoka (2002) measured SES by the 
highly problematic means of asking participants about their perceptions about neighbourhood resources and safety, which is at best only a tangential and indirect measure of SES. In contrast, the current study measured SES using the more robust and sensitive Scottish Index of Multiple Deprivation (SIMD).

\section{Self-Efficacy Beliefs and Gender}

Male high school students reported significantly more positive postsecondary destination self-efficacy beliefs than females, despite being at greater risk of failing to actually obtain a positive destination. There was also a significant interaction between gender and SES which showed this greater self-efficacy belief in males was more pronounced at higher levels of deprivation. This raises the possibility that the level of self-efficacy belief expressed by male high school students, particularly those living in areas of higher social deprivation, may represent a relative over-confidence in their ability to perform the target behaviour of obtaining a positive postsecondary destination, when compared to females.

This interpretation is supported by Brown and Lent (2006), who argued that selfefficacy beliefs that are significantly discrepant from ability, to the extent that they indicate over confidence, can be maladaptive and ultimately result in disappointment and hindrance. They argue that SCCT posits that career goals "might be most effectively and efficiently reached by aiding adolescents to........acquire self-efficacy beliefs in areas of strength that are commensurate with ability but sufficiently challenging to foster further skills development ", (Brown \& Lent, 2006, p. 215). This position is also congruent with Bandura (1986), who argued that self-efficacy beliefs which moderately exceed existing objectively measured ability are most favourable in terms of their ultimate positive impact on performance levels.

\section{The Sources of Self-Efficacy Beliefs and Gender}

Significantly lower scores with regard to the career learning experience of past performance were reported by male students. This means that males perceived that they had less previous learning experience of success in a part time job or work experience than females. This result is consistent with the finding of Anderson and Betz (2001), who reported that male university students in the USA had lower scores than females for a measure of past performance of career relevant social skills. This finding of the current study is also congruent with one of the core hypotheses common to SCCT (Lent, Brown, \& Hackett, 1994) and CSM (Brown \& Lent, 2018; Lent et al. 2017; Lent \& Brown, 2013): that the level of 
career performance an individual attains is derived in part from their previous experience of career-relevant past performance. Therefore, it may be reasoned that the significantly lower levels of career-relevant past performance reported by males in the current study could potentially contribute to an understanding of why male school leavers are at greater risk of failing to obtain a positive postsecondary destination.

Against expectation, the results of the current study showed that male high school students reported significantly higher levels of positive emotional arousal when thinking about their postsecondary career prospects. This means that males were more likely to report being confident about their career prospects and feeling good as a result, as opposed to being worried about failure and feeling bad in consequence. It should be noted however, that this finding was inconsistent with the previous study by Anderson and Betz (2001), who found no difference between male and female university students in absolute levels of career-related emotional arousal. However, the Social Self-Efficacy Scale (SSSS) used by Anderson and Betz (2001) measured emotional arousal using items such as "Social situations make me feel uneasy and confused", which, it could be argued, lack the domain specificity in relation to their specific target behaviour of being able to choose a career. This has been highlighted by Bong (2006) as a common error in such studies. In contrast, the emotional arousal items used in the current study asked specifically about students' emotional responses when they thought about success and failure to achieve a positive postsecondary destination, which directly corresponded to the self-efficacy items used in the current study that asked about students' confidence they could perform that specific target behaviour.

\section{Limitations}

The study was carried out in six schools from a single local authority in Scotland, UK. This raises questions about the generalisability of the findings and highlights the need to repeat the study and generate more data on the reliability and validity of the scales employed in different contexts and cultures. It is also important to recognise that the link between selfefficacy and its sources, and the actual target behaviour of being able to attain a positive postsecondary destination was not measured directly in the current study.

\section{Implications for Practice, Policy and Future Research}

The study suggests that educational interventions involving focused learning experiences designed to increase self-efficacy beliefs about obtaining postsecondary 
destinations may be an effective way to improve postsecondary outcomes for high school students from areas of higher social deprivation. These interventions could include targeted vicarious learning experiences, involving exposure to successful career role models, particularly those who students perceive as being similar to them. Interventions to address the relative over-confidence found in males, particularly those living in areas of higher social deprivation, could include additional learning experiences which enable them to form more evidence-based self-efficacy beliefs. The evidence suggests that it could be beneficial if these beliefs were more securely anchored in direct and personal experience of positive past performance in vocational activities. This could be achieved, for example, by interventions that involve additional, intensively-mentored work experience.

In contrast, the relatively negative career-oriented emotional arousal found in females suggests that rather different learning experiences could be more effective for them. Educational interventions based on Cognitive Behaviour Therapy (CBT) could be used to teach students how to identify, challenge and take control of the links between careeroriented thoughts, feelings and behaviours. This could be achieved at a group level using materials from the FRIENDS programme for example (Higgins \& O'Sullivan, 2015; Barrett, 2005) and at an individual level using the Think Good Feel Good resources (Stallard, 2005).

The Scottish and English governments in the UK already provide guaranteed, fully funded, first destination opportunities to all school leavers, together with financial incentives to encourage student uptake. Some of these are targeted specifically on vulnerable students from geographical areas and local communities with high levels of deprivation. However, in the light of the findings of the current study, it could be potentially beneficial if SES and gender were given still greater recognition as risk factors for failure to achieve a positive postsecondary destination. It could also be advantageous if the measurement scales developed in the current study were recommended in central and local authority policy guidance to schools. These could be introduced as enabling assessment tools for teachers and other career professionals to identify those young people at greatest risk of failing to obtain a positive postsecondary destination. The scales could be used in informing the selection of which young people should be recruited into which educational interventions.

However, the limitations noted above indicate that substantial research tasks remain. These include the need for a process of ongoing empirical development of the measurement 
scales employed to increase the number of items and improve validity and reliability. This would produce more evidence about the generalisablity and variability of the findings in other geographies and cultures. These tasks could be undertaken through action research projects implemented at practitioner level by teachers and career development professionals. This would also enable further empirical testing and refinement of hypotheses about the existence of different ways of thinking about their future career within different demographic groups of children and young people, which require differentiated learning experiences and interventions.

\section{Conclusions}

The results show that self-efficacy beliefs about the ability to obtain a postsecondary destination in employment, education or training vary with regard to the factors of SES and gender. The hypotheses of the study were partly confirmed. As predicted, fewer positive destination self-efficacy beliefs and less vicarious experience of success in education or employment were reported by young people who lived in more socially deprived geographical areas. As predicted, male students reported fewer positive perceptions of having

personally experienced previous success in education or employement than females. Two statistically significant relationships were detected which were in the opposite direction from the hypotheses. Against expectations, male students were found to report more positive destination self-efficacy beliefs than females, and females students were found to report more negative emotional arousal in relation to their thinking about the post secondary transition.

As discussed, these discovered effects have the potential to help clarify why high school students who live in more socially deprived geographical areas, and males in particular, are over represented in those who fail to attain a positive postsecondary destination in employment education and training and join the ranks of unemployed youth. This presents a significant social justice challenge at the levels of practice, policy and future research. The differences found in self-efficacy beliefs and their learning sources suggest good prospects for assessment-based targeting of differentiated practitioner interventions with different groups of high school students. This has clear potential to inform and improve, not only the provision of equal postsecondary opportunities in employment, education and training, but also the enabling of psychological readiness in all young people to take advantage and benefit from such opportunities. 


\section{References}

Ahn, H. S., Bong, M., \& Kim, S. I. (2017). Social models in the cognitive appraisal of self-efficacy information. Contemporary Educational Psychology, 48, 149-166.

Anderson, S. L., \& Betz, N. E. (2001). Sources of social self-efficacy expectations: Their measurement and relation to career development. Journal of Vocational Behavior, 58(1), 98117.

Anders, J., \& Dorsett, R. (2017). What young English people do once they reach school-leaving age: A cross-cohort comparison for the last 30 years. Longitudinal and Life Course Studies, 8 (1), 75-103.

Bäckman, O., \& Nilsson, A. (2016). Long-term consequences of being not in employment, education or training as a young adult. Stability and change in three Swedish birth cohorts. European Societies, 18(2), 136-157.

Bandura, A. (1977). Self-efficacy: Toward a unifying theory of behavioural change. Psychological Review, 84(2), 191-215.

Bandura, A. (1986). Social foundations of thought and action: A social cognitive theory. Upper Saddle River, NJ: Prentice-Hall.

Bandura, A. (1989). Human agency in social cognitive theory. American Psychologist, 44(9), 11751184.

Bandura, A. (1997). Self-efficacy: The exercise of control. New York: Macmillan.

Bandura, A. (2006). Guide for constructing self-efficacy scales. Self-efficacy beliefs of adolescents, In T. Urdan \& F. Pajares (Eds.), Self-efficacy beliefs of adolescents (pp.307-337). Greenwich, CT: Information Age Publishing.

Barrett, P. M. (2005). FRIENDS for life: Group leader's manual for youth. Brisbane: Australian Academic Press.

Betz, N., Borgen, F., \& Harmon, L. (1996). Skills confidence inventory applications and technical guide. Palo Alto: Consulting Psychologists Press.

Betz, N. E., Klein, K. L., \& Taylor, K. M. (1996). Evaluation of a short form of the career decisionmaking self-efficacy scale. Journal of Career Assessment, 4(1), 47-57.

Betz, N. E., \& Hackett, G. (2006). Career self-efficacy theory: Back to the future. Journal of Career Assessment, 14(1), 3-11.

Betz, N.E., \& Taylor, K. M. (2013). The career decision self-efficacy scale manual and sampler set. Menlo Park, CA: Mind Garden Inc.

Bong, M. (2006). Asking the right question: How confident are you that you could successfully perform these tasks, In T. Urdan \& F. Pajares (Eds.), Self-efficacy beliefs of adolescents (pp.287-305). Greenwich, CT: Information Age Publishing. 
Brace, N., Kemp, R. \& Snelgar, R. (2012). SPSS for Psychologists. Basingstoke: Palgrave Macmillan.

Brown, S. D., \& Lent, R. W. (2018). Promoting adaptive career behavior: A Social Cognitive

Career Theory perspective. In L. Nota \& S. Soresi (Eds.), Counseling and coaching in times of crisis and transition: From research to practice (p. 103-112). Abingdon: Routledge/Taylor \& Francis Group.

Brown, S. D. \& Lent, R. W. (2006). Preparing adolescents to make career decisions. In T. Urdan \& F. Pajares (Eds.), Self-efficacy beliefs of adolescents (pp.201-223). Greenwich, CT: Information Age Publishing.

Butz, A. R., \& Usher, E. L. (2015). Salient sources of early adolescents' self-efficacy in two domains. Contemporary Educational Psychology, 42, 49-61.

Cattell, R. B. (1966). The scree test for the number of factors. Multivariate Behavioral Research, 1(2), 245-276.

Chin, D., \& Kameoka, V. A. (2002). Psychosocial and contextual predictors of educational and occupational self-efficacy among Hispanic inner-city adolescents. Hispanic Journal of Behavioral Sciences, 24(4), 448-464.

Coles, B., Hutton, S., Bradshaw, J., Craig, G., Godfrey, C. and Johnson, J. (2002). Literature Review of the Costs of being 'Not in Education, Employment or Training' at Age 16-18. London: Department for Education and Skills, Research Report 347. Retrieved from https://www.researchgate.net/profile/Christine_Godfrey/publication/255630130_Literature_R eview_of_the_Costs_of_Being_Not_in_Education_Employment_or_Training_at_Age_1618/links/0deec539afcfea0208000000.pdf (accessed 7 June 2020).

Collins, C. W., McLeod, J., \& Kenway, J. (2000). Factors influencing the educational performance of males and females in school and their initial destinations after leaving school. Canberra: Department of Education, Training and Youth Affairs. Retrieved from http://citeseerx.ist.psu.edu/viewdoc/download?doi=10.1.1.460.4402\&rep=rep1\&type=pdf (accessed 7 June 2020).

Cooke, G. (2013). No more NEETS. A plan for all young people to be learning or earning, report of the Institute for Public Policy Research. Retrieved from http://www.tenantadvisor.net/wpcontent/uploads/2013/11/no-more-neets_Nov2013_11516.pdf (accessed 4 June 2020).

Echeverría Castro, S. B., Sotelo Castillo, M. A., Acosta Quiroz, C. O., \& Barrera Hernández, L. F. (2020). Measurement Model and Adaptation of a Self-Efficacy Scale for Mathematics in University Students. SAGE Open, 10(1), 2158244019899089

Feng, Z., Everington, D., \& Ralston, K. (2015). Consequences, risk factors, and geography of young people not in education, employment or training (NEET). Retrieved from http://dera.ioe.ac.uk/24628/1/00487865.pdf (accessed 4 June 2020). 
Genda, Y. (2007). Jobless youths and the NEET problem in Japan. Social Science Japan Journal, 10(1), 23-40.

Hanson, J., Codina, G., \& Neary, S. (2017). Transition programmes for young adults with SEND. What works? London: The Careers \& Enterprise Company.

Higgins, E., \& O'Sullivan, S. (2015). "What Works": systematic review of the "FRIENDS for Life" programme as a universal school-based intervention programme for the prevention of child and youth anxiety. Educational Psychology in Practice, 31(4), 424-438.

Lent, R. W., Brown, S. D., \& Hackett, G. (1994). Toward a unifying social cognitive theory of career and academic interest, choice, and performance. Journal of Vocational Behavior, 45(1), 79122.

Lent, R. W., Brown, S. D., \& Hackett, G. (2000). Contextual supports and barriers to career choice: A social cognitive analysis. Journal of Counselling Psychology, 47(1), 36-49.

Lent, R. W., \& Brown, S. D. (2013). Social cognitive model of career self-management: Toward a unifying view of adaptive career behavior across the life span. Journal of Counseling Psychology, 60(4), 557.

Lent, R. W., Ireland, G. W., Penn, L. T., Morris, T. R., \& Sappington, R. (2017). Sources of selfefficacy and outcome expectations for career exploration and decision-making: A test of the social cognitive model of career self-management. Journal of Vocational Behavior, 99, 107117.

Maguire, S. M., \& Thompson, J. (2007). Young people not in education, employment or training (NEET): where is Government policy taking us now? Youth and Policy, 8(3), 5-18.

Neumark, D. (Ed.). (2007). Improving school-to-work transitions. New York: Russell Sage Foundation.

Sanderson, E. (2019). Youth transitions to employment: Longitudinal evidence from marginalised young people in England. Journal of Youth Studies, 28, 1-20.

Schoon, I. (2020). Navigating an uncertain labor market in the UK: The role of structure agency in the transition from school to work. The ANNALS of the American Academy of Political and Social Science, 688(1), 77-92.

Schoon, I. (2014). Parental worklessness and the experience of NEET among their offspring. Evidence from the Longitudinal Study of Young People in England (LSYPE). Longitudinal and Life Course Studies, 5(2), 129-150.

Scottish Government (2012a). Opportunities for all: Supporting all young people to participate in post-16 learning, training or work. Retrieved from https://www.gov.scot/publications/opportunities-supporting-young-people-participate-post16-learning-training-work/ (accessed 4 June 2020) 
Scottish Government (2012b). The Scottish Index of Multiple Deprivation: Background methodology. Retrieved from https://www2.gov.scot/Topics/Statistics/SIMD/Methodology (accessed 4 June 2020)

Scottish Government (2013). The Scottish Index of Multiple Deprivation post code lookup. Retrieved from http://www.gov.scot/Topics/Statistics/SIMD/SIMDPostcodeLookup (accessed 4 June 2020).

Simmons, R., Connelly, D., \& Thompson, R. (2020). 'Education ain't for us': using Bourdieu to understand the lives of young White working-class men classified as not in education, employment or training. Research in Post-Compulsory Education, 25(2), 193-213.

Skills Development Scotland (2014). School leaver destinations. Initial follow_up 2013/14. National. December 2014. Retrieved from https://www.skillsdevelopmentscotland.co.uk/publicationsstatistics/ (accessed 23 February July16).

Skills Development Scotland (2015). Glasgow City Council: Community partnership report. Initial school leaver destination returns. December 2014. Retrieved from https://www.skillsdevelopmentscotland.co.uk/publications-statistics/ (accessed 2 March 2016).

Stallard, P. (2005). A clinician's guide to think good-feel good: Using CBT with children and young people. Chichester: John Wiley \& Sons.

Usher, E. L., \& Pajares, F. (2008). Sources of self-efficacy in school: Critical review of the literature and future directions. Review of Educational Research, 78(4), 751-796.

Valiente, O., Lowden, K., \& Capsada-Munsech, Q. (2020). Lifelong learning policies for vulnerable young adults in post-recession Scotland. British Journal of Sociology of Education, 41(2), 218-233.

Received: $17-02-2020$

Accepted: 20-05-2020 